\title{
O CEARÁ E A INDÚSTRIA TÊXTIL NO ESPAÇO-TEMPO
}

\author{
CEARÁ STATE AND THE TEXTILE INDUSTRY IN TIME-SPACE \\ CEARÁ Y LA INDUSTRIA TEXTIL EN EL ESPACIO-TIEMPO
}

\author{
Alexsandra Maria Vieira Muniz - Universidade Estadual do Ceará - Fortaleza - Ceará - Brasil \\ geoalexia@gmail.com
}

\begin{abstract}
Resumo
Tendo como objetivo analisar a indústria têxtil e a trama de relações socioespaciais que ela interliga, neste estudo realizamos um resgate da formação e desenvolvimento da Indústria têxtil cearense, desde sua implantação, passando pelos anos de 1980, chegando aos nossos dias, em outro contexto do capital industrial sob a atuação do Estado com 0 atual modelo da política de industrialização. No encaminhamento desta análise, buscamos explicitar como a atividade industrial têxtil participa da produção do espaço cearense. Para tanto, fizemos uso tanto de pesquisa bibliográfica, como de pesquisa estatística e de campo. Desta forma, a importância deste estudo tornou-se notória, uma vez que permitiu evidenciar o papel que desenvolve a indústria no espaço cearense e as relações socioespaciais construídas ao longo do tempo.
\end{abstract}

Palavras-chave: indústria, espaço, Geografia.

\section{Abstract}

Having as objective to analyze the textile industry and the web of socio-spatial relations that it connects, in this study we look back to the training and development of the textile industry in Ceará, since its inception, through the 1980s, until the present day, in another context of industrial capital under the state action with the current model of industrialization policy. In the analysis, we tried to explain how the textile industrial activity participates in the production of Ceará space. To this end, we used both the literature as statistical and field research. Thus, the importance of this study became notorious as it has highlighted the role that the industry develops in Ceará space and the socio-spatial relationships built over time.

Keywords: industry, space, Geography.

\section{Resumen}

Con el objetivo de analizar la industria textil y la red de relaciones socio-espaciales conectadas, en este estudio se rescató y desarrolló la industria textil en Ceará, desde su creación, pasando por la década de 1980, hasta nuestros días, en otro contexto del capital industrial y bajo la actuación del Estado con el modelo actual de la política de industrialización. Al comunicar este estudio buscamos explicar cómo la actividad industrial textil participa en la producción del espacio cearense. Con este fin, se utilizó tanto la literatura bibliográfica como la investigación estadística y de campo. Por eso, la importancia de este estudio se hizo notoria al permitir colocar en destaque el papel que desarrolla la industria en el espacio cearense y las relaciones socio-espaciales construidas a lo largo del tiempo.

Palabras-claves: industria, espacio, Geografía.

Introdução

O desenvolvimento da indústria têxtil no Ceará está intrinsecamente relacionado com o contexto sócio-histórico e econômico de formação e ocupação do espaço cearense. 
A implantação da indústria têxtil no Ceará foi favorecida pela disponibilidade da matéria-prima (algodão), tendo sido seu beneficiamento impulsionado no período pós-Guerra de Secessão (1862-1866).

Conforme Nobre (2001), a industrialização, que não se restringe exclusivamente às fábricas de fiação e tecelagem, decorre de vários fatores, sendo eles: os saldos do comércio externo acumulados na fase de alta dos preços do algodão, os excedentes gerados com a venda de escravos para outras províncias e ainda a assistência financeira do Governo Federal por ocasião da grande seca de 1877.

Na perspectiva de Aragão (2002, p. 71), outros fatores que impulsionaram o investimento na indústria têxtil foram "o preço desse produto no mercado, a criação de uma infra-estrutura capaz de sustentar a produção e comercialização do produto, incluindo aí o próprio papel do Estado e, sobretudo, as possibilidades de acumulação de capital oriundas da comercialização do algodão”.

Desta forma, o desenvolvimento da indústria têxtil no espaço-tempo cearense pode ser dividido em quatro fases, conforme Aragão (1989; 2002): $1^{\text {a }}$ fase - 1882 a 1900 (os Pioneiros), $2^{\text {a }}$ fase - 1900 a 1960 (os Empreendedores), $3^{\mathrm{a}}$ fase -1960 a 1980 (os Modernos - Incentivos Fiscais e Transformações) e 4a fase - 1980 em diante (a geração Empresarial).

Embora o impulso à industrialização no período atual venha de um processo que se desenvolve bem antes da primeira fase, ou seja, antecede ao final do século XX, faremos, de forma sucinta, um resgate do desenvolvimento industrial têxtil cearense em cada fase até chegar aos nossos dias.

\section{0 desenvolvimento industrial têxtil: dos "pioneiros" aos "modernos"}

A indústria têxtil é constituída pelos segmentos de fiação, tecelagem, acabamento e confecção. Estes segmentos industriais são autônomos, porém, estão inter-relacionados, já que o produto final de cada uma dessas fases é a matéria-prima da fase seguinte. O processo produtivo é muito diversificado, ou seja, algumas indústrias têxteis podem possuir uma ou algumas fases da produção (somente fiação, apenas tecelagem, só beneficiamento ou unicamente fiação e tecelagem etc.), outras podem ter todas as etapas do processo têxtil (fiação, tecelagem e beneficiamento), o que seria uma indústria verticalizada, com todos os processos. Existem outros processos intermediários, como, por exemplo: engomadeira ou engomagem. 
Até chegar ao produto final, existe ainda uma interface com a indústria química em razão da necessidade de insumos (corantes têxteis, pigmentos têxteis, produtos auxiliares etc.) para diversos tipos de tratamento, desde as fibras (além das fibras naturais, há as manufaturadas) até os bens acabados, bem como, com os sistemas técnicos ligados à indústria de bens de capital, haja vista as máquinas e equipamentos que perpassam o processo produtivo.

Como ressalta Aragão (2002, p. 69),

A industrialização de tecidos e fios no Ceará, diferentemente de outros Estados, que investiram no setor desde o começo do século XIX, só vai ocorrer nas duas últimas décadas do século XIX, considerando-se que a primeira fábrica têxtil, a Fábrica Progresso, que foi idealizada em 1881 e registrada em 1882 com o nome de Pompeu \& Irmãos, veio efetivamente a funcionar em 1883.

A indústria têxtil cearense, além de ter ligação com o espaço e história socioeconômica, tendo origem no capital local vinculado à economia cearense, causou ao longo do tempo transformações socioespaciais notáveis, não só nas cidades de origem como também onde permanece e onde mantém relações comerciais por meio do espaço da circulação de seu produto final e compra de matérias-primas.

Como sabemos, a pecuária e o algodão, constituindo o binômio gado-algodão, foram atividades econômicas que se destacaram em escala regional.

Já no final do século XVIII, o cultivo do algodão começou a despontar como importante atividade econômica. O algodão nordestino veio substituir a produção algodoeira americana, principal abastecedora de cotton, para as indústrias têxteis inglesas. A paralisação da produção do algodão dos Estados Unidos se deveu à Guerra de Secessão (1860-1865), entre o sul e o norte dos Estados Unidos. Durante o período dessa guerra, que abriu o mercado mundial para a produção cearense, o algodão substituiu o charque em importância econômica. Algodão e gado, todavia, não se colocavam como atividades excludentes, pelo contrário, passaram a ser o binômio determinante no desenvolvimento da região.

Em meados do século XIX, o algodão passou a ser o principal produto de exportação, sendo notória a importância que teve seu cultivo e beneficiamento para o destaque de cidades cearenses.

Como ensina Girão (2000, p. 223), "as principais regiões produtoras do algodão eram os distritos de Fortaleza e Aracati e as serras de Baturité, Uruburetama, Meruoca, Pereiro e Aratanha". 
O desenvolvimento da lavoura algodoeira e a colocação desse produto no mercado internacional provocaram a projeção de Fortaleza como centro urbano. Pouco a pouco, a capital cearense foi adquirindo destaque entre as cidades do Estado e, posteriormente, entre as cidades brasileiras (Silva, 2002, p. 229).

No lugar do porto de Aracati, que no passado estava ligado ao couro e ao charque, o porto de Fortaleza foi escolhido como local de exportação.

Conforme Silva (2012, s./p.),

A construção da Estrada de Ferro de Baturité e a conexão do trem com o porto marcam o período da economia calcada no cultivo do algodão num contexto muito favorável ao Ceará e a Fortaleza. A cidade abre-se ao mundo e amplia sua relação com o sertão.

Na expressão de Elizabeth Aragão (1989, p. 20),

[...] a Indústria têxtil no Ceará, considerando exclusivamente o Setor de Fiação e Tecelagem, se instala a partir da década de 80 do século passado, percorrendo um período de efervescência que se prolonga até 1930, o qual permanece substancialmente inalterado até os meados de 1950. De 1930 a 1940 ela vive momentos de fraco crescimento-estagnação e a partir de 1939 é revitalizada com a explosão da Segunda Guerra Mundial parando gradualmente na década de 1950.

Assim, temos o impulso à instalação de indústrias têxteis em inúmeros municípios cearenses, como Sobral, Aracati e, notadamente, Fortaleza.

Com o aproveitamento industrial do algodão, através de indústrias de tecidos em Fortaleza, inicia-se o período fabril cearense e a capital, além de exercer o papel de grande centro coletor e beneficiador de produtos primários, torna-se aos poucos centro de transformação da produção primária. (Silva, 1994, p. 87).

Em razão do beneficiamento do algodão pelas indústrias têxteis, conforme Cruz (2002) observa-se, então, um novo sistema técnico (armazéns, teares, fábrica de beneficiamento) e novas relações de trabalho.

O uso do espaço cearense pelos "senhores do algodão" explica-se pela relação do mundo com o lugar, pois, segundo Takeya (1995), são os problemas conjunturais ocorridos nos Estados Unidos da América que alavancam a cotonicultura e todo seu aparato técnico. 
Contudo, sabemos que não foram somente as crises internas dos Estados Unidos, mas também o fato de que a região Nordeste produzia na época um algodão diferenciado conhecido como "algodão mocó”, de fibra longa, que servia mais eficazmente ao setor produtivo nacional e internacional.

Como no período da pecuária, o espaço rural serviu de primeiro lastro para que o sistema técnico do algodão aportasse, mais tarde, aos espaços urbanos, pois a evolução deste processo de produção segue um caminho que tem como espaço de partida o descaroçamento/fiação no interior das fazendas e como "território do avanço" as cidades, como é o caso do Aracati com suas usinas de beneficiamento.

Assim, após uma longa fase como atividade rural, o algodão ganhou espacialidade no urbano aracatiense.

Cabe aqui atentar para a intervenção pela técnica, da relação deste espaço urbano tecnificado com espaços externos (nacional e mundial). O modo como as usinas desenharam uma nova cartografia, pautada por uma solidariedade organizacional traçada com origem na cotonicultura que incrementa antes as áreas rurais, para depois incrementar a cidade, a sua economia e, consequentemente, a sua urbanidade. As crises, no principal país da América Anglo-Saxônica, alavancam uma relação mundo-lugar-mundo, que faz o Ceará e especificamente a cidade de Aracati, e posteriormente, Fortaleza ocupar posição de destaque. “Já que a técnica é também social, pode-se lembrar que sistemas de objetos e sistemas de ações em conjunto constituem sistemas técnicos, cuja sucessão nos dá a história do espaço geográfico.” (Santos, 2008, p. 332).

A verticalidade imposta pelo cenário externo, seguida de uma horizontalidade que demanda de tais externalidades, perfaz um contexto que revela a importância das indústrias na expansão urbana cearense.

Na informação de Sousa (1922, p. 21), a cidade de Aracati era "relativamente comercial e industrial, possuindo importante fábrica de tecidos crus”. No ano de 1893, foi fundada a indústria têxtil Santa Thereza, em Aracati, com a denominação de Companhia Popular Aracatyense.

Para Aragão (1989; 2002), o período de 1882 a 1900 constitui a primeira fase de desenvolvimento da indústria têxtil no Estado do Ceará, sendo esta fase chamada de "os pioneiros", dada a coragem dos que ingressaram no ramo têxtil, até então, não explorado na economia do Ceará. Esta fase se caracteriza pela implementação das primeiras indústrias têxteis 
no Estado, quais sejam: Fábrica Progresso/ Pompeu \& Irmãos (1882- Grupo Thomaz Pompeu); Cia. Fáb. de Tecidos União Comercial (1891); Cia. Fabril Cearense de Meias (1891); Fábrica Santa Thereza (1893); Fábrica Ceará Industrial (1894); Fábrica Sobral (1895). Podemos constatar que das seis indústrias têxteis do primeiro período, somente uma, a Fábrica Progresso, foi fundada na década de 1880. Isto pode ser explicado devido às políticas protecionistas à indústria têxtil que só se intensificam na década de 1890 .

A primeira indústria a localizar-se fora de Fortaleza foi a Fábrica Santa Thereza, que, em 1893, foi fundada em Aracati, constituindo a $4^{\mathrm{a}}$ indústria têxtil cearense. A segunda indústria a instalar-se longe da Capital no final do século XIX foi a Fábrica de Tecidos Sobral, que se instalou nessa cidade em 1895.

A interiorização da indústria têxtil sucedeu no contexto em que o cultivo do algodão se expandiu fora da capital, criando um espaço produtor de matéria-prima para alimentar indústrias locais em Sobral, Aracati, Fortaleza e fora do Estado. Sendo assim, "os primeiros estabelecimentos industriais implantam-se nas cidades coletoras dos produtos agrícolas e em Fortaleza, principal ponto de escoamento da produção cearense”. (Amora, 2005, p. 371-372).

O aparecimento das primeiras indústrias têxteis cearenses é viabilizado por via capital próprio dos investidores locais, oriundo dos excedentes do comércio e sem a proteção do Estado. Cabe ressaltar o fato de que, dentre os industriais deste período, havia aqueles que ocupavam cargos na política cearense, Thomaz Pompeu (deputado, e seu cunhado e sócio, Nogueira Accioly que foi várias vezes Presidente do Ceará) e Ernesto Deocleciano (vice de Nogueira Accioly).

O período de consolidação da indústria têxtil no Brasil (Stein, 1979) corresponde à segunda fase da industrialização no Ceará, que, conforme Aragão (1989; 2002, p. 77), emerge em 1900, inaugurando um período que se estende até o final da década de 1950, período este denominado de geração dos empreendedores "porque mostram traços de iniciativa, agressividade, sendo eternos farejadores de oportunidades, vocacionados para o risco, apresentando grande dosagem de criatividade no ato de administrar".

As indústrias que se desenvolveram na segunda geração podem ser relacionadas, a seguir: Santa Elisa (1904); Santo Antônio (1929); Usina Gurge 1 (1916); Fiação Santa Maria (1918); Fiação São Luís (1928); Fábrica Baturité (1927); Fábrica São José (1926); Fábrica Santa Cecília (1945); Maranguape (1924). 
Apesar da escassez de dados que resgatem o desenvolvimento da indústria têxtil no Estado, cabe destacar a representatividade da Fábrica de Tecidos São José que produzia tecidos grossos, como algodãozinho, mescla e lonita, bem como fios e redes populares. Conforme Aragão (2002, p. 184), esta fábrica ocupava "área de $10.000 \mathrm{~m}^{2}$, no bairro de Jacarecanga, em Fortaleza, estando equipada com maquinaria moderníssima oriunda da Inglaterra, Alemanha e Estados Unidos, com capacidade para 6.800 fusos, ocupando 300 operários sob a direção de técnicos ingleses".

O maior número de operários se revela também após sua fundação: "Tal empreendimento teve grande expressão social e econômica, considerando que no período da $2^{\mathrm{a}}$ Guerra Mundial empregava um contingente de 1.050 funcionários". (Aragão, 2002, p. 79).

O impacto das indústrias têxteis, além dos aspectos técnicos, econômicos e sociais, se faz perceber notadamente no espaço, mediante a produção e reprodução espacial com as inter-relações capital e trabalho sob mediação das forças produtivas e relações sociais de produção.

A construção de vilas operárias para a reprodução da classe trabalhadora por meio das indústrias têxteis (como a São José, Baturité, as do grupo A. D. Siqueira, a Fábrica Santa Thereza, Santa Cecília, Sobral e Progresso) revela as interações na dinâmica urbana da Capital, uma vez que as vilas operárias continuaram se transformando, acompanhando a expansão da cidade.

[...] o setor de fiação e tecelagem implantou-se no fim do século XIX, mas é somente a partir de 1920 que surgem as vilas operárias. Isso se explica pelo fato de que é nesse momento que o setor busca sua expansão e a organização de sua produção de forma mais sistemática e contínua. (Andrade, 1990, p. 283).

Como na geração anterior, as indústrias instaladas nesta geração provinham de recursos dos próprios investidores, entretanto, diferentemente da fase anterior, aqui se tem como forma jurídica "sociedade por quotas de responsabilidade limitada” e não mais "sociedades anônimas". Ademais, dentre as vantagens advindas da primeira geração, Aragão (1989, p. 70; 2002, p. 77) cita: "a formação de uma inexpressiva mão-de-obra operária, a abertura de mercados e o aproveitamento de uma infraestrutura relativa ao suprimento de matéria-prima [...]."

Quanto a caracterização dos industriais desta fase, enquanto os 
[...] industriais da primeira geração, cujas famílias tinham alto nível de educação formal e suporte financeiro, [...], os desta segunda geração foram comerciantes, antes de se tornarem industriais têxteis, via de regra, desenvolvendo suas atividades mercantis no setor da compra e venda de algodão, sendo que alguns se tornaram, também, empreendedores das fábricas de beneficiamento de algodão, [...]. Outros, [...]tiveram nas atividades de transformação de óleo e sabão suas primeiras atividades manufatureiras. (Aragão, 2002, p. 78).

Quanto à origem dos industriais desta fase, provinham de "municípios do Ceará e que vêm para a Capital em busca de ampliação e sedimentação de negócios. Ressaltamos a figura de Antônio Diogo de Siqueira que veio a tornar-se o maior empresário têxtil do Ceará [...]" (Aragão, 2002, p. 78).

No Ceará, conforme Amora (2005, p. 372), "na década de 1950, as indústrias praticamente desaparecem, restando apenas alguns marcos como a Fábrica de Tecidos Progresso, sediada em Fortaleza”.

Uma vez que o Plano de Metas beneficiava o Centro-Sul do Brasil, a ausência de um parque industrial moderno e dinâmico dificultou a inserção do Nordeste na economia nacional e internacional no início dos anos de 1950 e, somente com a implantação do Estado Desenvolvimentista, nos anos de 1960, é que se buscaram as condições para um melhor desempenho das forças produtivas nessa Região.

De 1960 a 1980, ocorreu a terceira fase de desenvolvimento da indústria têxtil no Estado do Ceará, sendo esta fase também chamada de "os modernos", dado o intuito de modernizar as indústrias têxteis por meio da substituição das máquinas de mais de 30 anos e reequipando-as por meio do Programa de Reequipamento da Indústria Têxtil contido no I Plano Diretor da SUDENE.

Das 61 indústrias têxteis do Nordeste incluídas no programa, oito eram do Ceará, quais sejam: Progresso, Santa Elisa, Santa Teresa, Cia. Gasparian do Norte, Santa Cecília, Baturité, Santa Maria, Sobral (Aragão, 1989).

Oliveira (1977) ressalta o papel da Superintendência de Desenvolvimento do Nordeste (SUDENE) na implantação do sistema de incentivos fiscais como forma de captação de recursos para viabilização do processo de industrialização na região.

Desta forma, o desenvolvimento do Nordeste teve como base os programas de transferência de recursos inter-regionais, apoiados em incentivos fiscais como o sistema 34/18, FINOR (Fundo de Investimentos 
para o Nordeste) e, mais recentemente, FNE (Fundo Constitucional de Financiamento do Nordeste).

Em razão das oportunidades dos incentivos e financiamentos de órgãos estatais que se iniciaram no Nordeste após 1960, no Ceará, há o desenvolvimento da indústria têxtil pela "terceira geração, por se situarem em uma fase de transição, não deixam de ser empreendedores, contudo, apresentam novas características, como a preocupação com a modernização do equipamento e com a circulação dos produtos no mercado nacional[...]”. (Aragão, 2002, p. 65).

Dentre as indústrias ativas nas décadas de 1960 e 1970, podemos citar: Progresso (Faliu em 1987); Santa Tereza (Faliu em 1987); Sobral; Maranguape (Faliu em 1982); São José (Faliu em 1983); Santa Cecília(fundiu para Unitêxtil em 1973); Gasparian com o projeto da Cia. Ceará Têxtil; Algodões Finos de Quixadá, que se tornou a Fiação Jangadeiro S/A; Induchenil; Chenille do Nordeste S/A (Chenosa); Indústrias de Meias Finas S/A; Linhas Seridó S/A; Santa Inês(Indústria Politêxtil S/A): fundiu para Unitêxtil em 1973; Passamanaria do Nordeste; Santa Lucia(fundiu para Unitêxtil em 1973); Indústria Têxtil Armando Pinto S/A; Master (Fechou em 2000); Unitêxtil; Finobrasa, da associação Otoch e Baquit e posteriormente Grupo Vicunha Unidade IV; Pemalex; Tapetelene.

Percebemos que na década de 1960 havia 15 indústrias têxteis no Ceará, dentre as quais, três já existiam desde o século XIX (Progresso, Santa Tereza e Sobral), além da permanência de mais três do início do século XX (São José, Santa Cecília e Maranguape), uma vez que faliram as de Antonio Diogo de Siqueira (Santo Antônio, São Luís, Santa Elisa e a parte têxtil da Ceará Industrial) no final dos anos 1950 e início de 1960, tendo sido o acervo do Grupo Diogo comprado pela Gasparian do Norte em 1961. Ademais, a Fábrica Baturité, de José Pinto do Carmo, pediu moratória em 1959, sendo judicialmente encerrada dez anos depois. Além do mais, a Usina Gurgel, de Teófilo Gurgel, e a Fiação Santa Maria presentes até então, já não existiam mais nos anos de 1960.

Por outro lado, percebemos o surgimento de mais nove indústrias, dentre as quais estavam as de grande porte, como a Algodões Finos de Quixadá Ltda, que se tornou a Fiação Jangadeiro S/A (do empresário Alberto Baquit), em 1964. A instalação de outras indústrias se deve à intervenção da SUDENE, principalmente a partir de 1965. A conjuntura interna do Ceará facilitou a consolidação dos incentivos federais, uma 
vez que se buscou uma modernização do Estado no primeiro governo de Virgílio Távora, de 1962 a 1966, principalmente em termos infraestruturais, pois além da "[...] criação de estradas (facilitando, assim, o escoamento da produção do Estado), foi em seu governo que a energia elétrica da usina de Paulo Afonso chegou ao Ceará”, tendo sido a precariedade destes fatores infraestruturais alegados para o fato do atraso no desenvolvimento industrial. (Aragão, 2002, p. 65).

Já na década de 1970 foram seis as indústrias têxteis que surgiram, dentre as quais a Unitêxtil (União Industrial Têxtil S/A). A Unitêxtil corresponde à fusão, em 1973, das indústrias Santa Tereza, com matriz em Aracati, e as filiais desta em Fortaleza: Santa Cecília, Santa Inês/Indústria Politêxtil S/A (1967) e Cia. Têxtil Santa Lúcia(1969) - todas pertencentes ao Cotonifício Leite Barbosa.

"Mais de 50\% das indústrias têxteis instaladas no Ceará eram de pequeno porte (empregando de 10 a 99 pessoas), em 1970, enquanto que as de grande porte (mais de 250 empregados) correspondiam apenas a 3,1\%”. (Aragão, 2002, p. 97). Dentre as de grande porte estava a Fiação Nordeste do Brasil S/A - Finobrasa (da associação Otoch e Baquit) que, diferentemente das indústrias que até então tinham a característica de serem administradas por membros da família, esta já apontava nova tendência, uma vez que era administrada com a contratação de técnicos especializados ou com formação científica.

Conforme Aragão (2002), o financiamento do FINOR permitiu um pequeno aumento no número de indústrias grandes, em 1975. Dentre as indústrias de fiação e tecelagem de grande porte estava a Master Tecidos Plásticos, a Finobrasa e a Tapetelene, enquanto que as pequenas se caracterizavam por serem malharias e confecções. Várias indústrias que haviam surgido na década de 1960 como Induchenil, Linhas Seridó, Armando Pinto e Meias Finas já não existiam mais na década de 1970. A Cia. Ceará Têxtil, do Grupo Gasparian, entrou em falência em 1971, sendo assumida, pelo Grupo Machado.

A análise dos proprietários das indústrias ativas nos 1960 e 1970 permitiu caracterizar os empresários da Terceira Geração em quatro tipos, como bem relata Aragão (2002, p. 100):

1) Empreendedores com envolvimento histórico familiar com o algodão, [...]. 2) O grupo dos iniciantes a empresários têxteis a partir das oportunidades oferecidas pela política de incentivos fiscais. [...]. 3) Há o grupo formado exclusivamente pela tradição de bordado 
em Maranguape, [...]. 4) Por último, a Master Tecidos Plásticos, que surge como sucedâneo natural de empreendimentos do Grupo Master[...].

O fato de os proprietários industriais serem, notadamente cearenses, mesmo com associação a empresários do Centro-Sul, "possibilitou que no Ceará fosse a própria burguesia local quem assumisse o comando da industrialização da era da SUDENE[...]", permitindo que "a indústria cearense continuasse atuando nos setores tradicionais” (ARAGÃO, 2002, p. 101).

Como exemplo temos, em 1973, a fundação da Finobrasa, com a instalação, no Ceará, do grupo Vicunha, dos empresários Jacks Rabinovich e Mendel Steinbruch, capitalistas do Centro-Sul que se associaram a empresários locais, no caso, o grupo dos Otoch e Baquit. A Finobrasa foi a única participação da indústria sulista no setor têxtil do Ceará no quadro de indústrias instaladas pela SUDENE.

Até a década de 1970, a maior concentração industrial localizava-se nos bairros Antônio Bezerra, Mucuripe, Parangaba, na avenida Francisco Sá e bairros ao longo desta, como também no entorno da via férrea, atraindo grande contingente de migrantes. O crescimento industrial, neste período deu-se de maneira espontânea e não obedeceu a nenhum planejamento urbanístico.

Neste percurso, temos o terceiro período de industrialização no Ceará, segundo Amora (2005), e a quarta geração da indústria têxtil, com os Novos Empresários e o Fortalecimento do Parque Industrial Têxtil no Final do Século XX (1980 a 2002), consoante Aragão (2002).

\section{A Indústria Têxtil adaptada a um Novo Contexto}

É diante de um contexto de crise econômica enfrentado pelo país nos anos de 1980 que chegamos à quarta fase de desenvolvimento da indústria têxtil no Estado do Ceará, sendo esta na perspectiva de Aragão (1989, 2002) chamada de "geração empresarial", se estendendo de 1980 até nossos dias.

Dentre os diversos problemas enfrentados pela indústria têxtil nos anos 1980 podemos citar a escassez no fornecimento da matéria-prima (algodão), o fato de as indústrias mais antigas resistirem à reestruturação, permanecendo com a maquinaria defasada, o que levou à extinção de muitas indústrias têxteis, pois não tinham capacidade de competir. 
Vejamos, as indústrias têxteis ativas na década de 1980, no Ceará: Santana Têxtil; TBM; Têxtil Baquit; Têxtil União; Vicunha Nordeste (Unidade I); Juozas(Cia. brasileira de Modas); TBM(Unidade II); Cotece; Filati Malhas (TBM Unidade V).

Na década de 1980 fechou a indústria centenária Thomaz Pompeu, junto com a unidade Pompeu Têxtil e a indústria Santa Thereza. Em 1982, fechou a indústria Maranguape; e no ano seguinte, foi a vez da indústria São José. Permaneceu nesta década a indústria Sobral, ainda do século XIX, que depois de um incêndio em maio de 1980, que destruiu totalmente a seção de fiação da fábrica, continuou o grupo Ernesto Deocleciano apenas com o setor de tecelagem. Também resistiu a esta onda de fechamentos a indústria Santa Cecília da primeira metade do século XX, que era de propriedade do Cotonifício Leite Barbosa, também dono da indústria que fechou em 1984 (a Santa Tereza), "estando abrigada na Unitêxtil desde 1973. Dentro do cenário das empresas têxteis nos anos 1980, a Unitêxtil era o maior empreendimento do Estado[...]". (ARAGÃO, 2002, p. 108).

Permaneceram, ainda na década de 1980, três indústrias têxteis dos anos 1960 (Passamanaria, Jangadeiro, Ceará Têxtil) e três indústrias têxteis da década de 1970 (Master, Unitêxtil e Pemalex).

Mesmo em meio às dificuldades enfrentadas surgiram nove indústrias têxteis modernas. Percebemos tanto o aparecimento de novas indústrias como também a ocupação de novos espaços pelo capital industrial, como o município de Maracanaú, reflexo da construção do Distrito Industrial de Maracanaú, ainda em 1963, embora só tenha iniciado o funcionamento nos anos de 1970, esse Distrito Industrial estava inserido no âmbito de incentivo ao desenvolvimento industrial proposto para o Ceará.

O quadro diverso do contexto nacional que se delineia nos anos de 1980 decorre em grande parte dos incentivos durante o Governo de Virgílio Távora, em sua segunda gestão, já que ao longo dos anos 1980 foram reduzindo os financiamentos industriais por parte da SUDENE.

Desta forma, no Ceará, as indústrias têxteis conseguiram superar a crise por meio da participação mais ativa do Governo Estadual e da parceria com o Governo Federal que, na tentativa de manter o crescimento da década anterior reforçaram os incentivos industriais.

Ao longo da década de 1980, na indústria têxtil, houve períodos de crescimento intercalados a outros de estabilidade ou retração. Somente a partir do segundo semestre de 1984, o setor têxtil apresentou sinais de recuperação. 
No Ceará, a ruptura política experimentada pelo Estado na passagem de 1986 para 1987 foi sem dúvida o marco político-institucional que permitiu renovar o discurso e a abordagem nos efeitos da seca, bem como significou uma mudança de paradigma na condução das políticas públicas Estaduais. Durante o primeiro “Governo das Mudanças”, de 1987 a 1991, foram dados passos decisivos na direção da montagem do novo modelo da gestão.

Dentre as "novidades" trazidas por esta nova elite que teve à frente inicialmente Tasso Jereissati, ganha destaque a política industrial, pautada, dentre outras estratégias, na guerra fiscal. Neste período, a SUDENE perde significado, sendo extinta durante o governo de Fernando Henrique Cardoso no ano de 2001 para só depois ser recriada em 2003, no governo Lula.

Dentre os principais instrumentos da atual política de industrialização, temos a concessão de incentivos fiscais/financeiros, de infraestrutura, o discurso da descentralização dos investimentos produtivos e a maior geração de empregos com o aproveitamento da mão de obra barata.

Com o enfraquecimento das políticas federais destinadas a combater as desigualdades regionais após a Constituição de 1988, o que se observa é o surgimento de políticas estaduais que modificam a dinâmica da economia local.

Assim, dentre os atrativos para alocação de indústrias embasados na política industrial, temos: a oferta de mão de obra, bem como serviços de água, esgotamento sanitário, energia, gás, portos e aeroportos, construção de estradas, sistemas técnicos ligados às comunicações, a oferta de distritos industriais que acompanha a infraestrutura necessária ao funcionamento das indústrias, mais recentemente os esforços de desconcentração regional têm envolvido a concessão de incentivos fiscais, com a isenção ou alíquota diferenciada de impostos.

No Ceará, destacam-se as políticas de incentivo à industrialização via Fundo de Desenvolvimento Industrial (FDI) mediante a isenção e prorrogação de incentivos fiscais, visando à implantação, realocação, ampliação, recuperação e modernização de indústrias. A política de atração de indústrias no Ceará data do governo Virgílio Távora (1962 - 1966), culminando com a promulgação da Lei n. 10.367, de 01 de dezembro de 1979, que instituiu o Fundo de Desenvolvimento Industrial do Ceará (FDI), tendo sido este uma estratégia gerida com o objetivo de dotar o Ceará do aporte legal para viabilizar o incentivo à industrialização. 
Com a institucionalização do FDI, o Ceará tornou-se pioneiro na adoção de incentivos fiscais e financeiros voltados para atração de novas empresas industriais no Estado, notadamente percebida pela isenção e prorrogação de impostos (incentivos fiscais), no intuito de dar apoio à implantação, modernização, realocação e ampliação destas.

O abatimento é maior quanto mais distante de Fortaleza for o estabelecimento. Para uma indústria que se instale em uma cidade da Região Metropolitana de Fortaleza (RMF), o incentivo se dá por dez anos. Se for de 300 a $500 \mathrm{~km}$, o incentivo se eleva para 13 anos e, por fim, se for além de 500 km de distância da RMF, se dá até 15 anos. O desconto do ICMS é menor para indústrias que se instalam na própria Capital, sendo de $45 \%$.

Essa política enseja diversos questionamentos como a possibilidade de gerar concorrência desigual com as indústrias existentes e a possibilidade indireta de reduzir a capacidade de poupança do governo.

Apesar das deficiências, o FDI e o FINOR foram instrumentos que auxiliaram no desenvolvimento das indústrias têxteis, de confecções, calçados e metal-mecânica do Estado. É importante ressaltar que esses instrumentos foram utilizados basicamente para atração de grandes empreendimentos industriais, ficando o apoio à pequena e média empresa fora desse foco.

Essas modificações começaram a ocorrer no momento em que o governo centrou as atenções para a reestruturação dos setores produtivos, como indústria, agricultura, turismo etc.

Conforme Aragão (2002, p. 37),

O Ceará se apresenta, hoje, como o segundo maior pólo têxtil do Brasil, no que se refere ao consumo de algodão em pluma, ficando atrás somente do Estado de São Paulo. Detém, ainda, o segundo lugar na produção de fios, sendo ultrapassado também por São Paulo. E dentro da cadeia produtiva, ocupa o quarto lugar em volume de produção, depois de São Paulo, Santa Catarina e Minas Gerais.

Na segunda metade dos anos 1980, como relata Amaral Filho (2003, p. 377), dentre as principais políticas públicas do Governo Estadual está "a nova política industrial, que introduz uma racionalidade industrial e espacial à concessão de incentivos financeiros, além de incluir um vetor dedicado ao apoio e à indução ao desenvolvimento industrial".

Diante do exposto, percebemos o Estado assumindo o papel de locomotiva das transformações mediante seu aparato institucional, 
adaptando a organização social, espacial e econômica às novas necessidades do capital e assim organizando um espaço apto ao desenvolvimento da atividade capitalista.

Em meio à política neoliberal, o processo de abertura comercial ganhou força, havendo uma elevação dos níveis de concorrência internacional. Como não poderia deixar de ser, o conjunto destas transformações teve implicações para a produção industrial.

A indústria nacional que, durante décadas, contou com a proteção estatal, neste novo cenário, teve que se remodelar, para não perder sua fatia no mercado nacional para importações mais baratas, e no mercado mundial, com a adesão de outros países ao processo de abertura comercial.

Diante de toda esta conjuntura vivenciada nos anos de 1990, as indústrias mais preparadas investiram na sua reestruturação, reduziram seus custos e melhoraram sua competitividade, com o objetivo de enfrentar a concorrência internacional.

Dentre as indústrias têxteis no Ceará que surgiram entre os anos 1990 a 2002, temos: Fiotex (Incorporou em 2001 a Cia. Ceará Têxtil); Micrel Benfio; Jaguatêxtil; Elizabeth Têxtil (Vicunha Unidade V); Fitesa Têxtil; CTN; Marcotex; Tebasa- Resultante da união entre Fiação Jangadeiro e a Têxtil Baquit; Aurora Têxtil; Cotefor; Lerma do Nordeste; Santa Rita; Pacajus (Vicunha Unidade III); Haco Etiquetas; Servitêxtil (Beatriz Têxtil); TBM (Unidade III).

Percebemos que de 1990 a 2002, surgiram mais indústrias do que nos anos de 1960, quando houve uma atuação mais intensa da SUDENE, uma vez que 16 novas indústrias têxteis foram instaladas no Ceará. Por outro lado, fecharam a Master Tecidos Plásticos, em 2000, e a fábrica centenária Sobral (Companhia de Fiação e Tecidos Ernesto Deocleciano) que funcionou até 1997, e hoje é a sede do Campus Tecnológico da UFC, em Sobral.

Das indústrias da década de 1980, quase todas continuaram na década de 1990 somente não se tem registro da Juozas (Cia. brasileira de Modas), que era voltada à produção de tecidos e era um dos fornecedores da Del Rio (adquirida por Carlos Pereira em 1968, responsável pela parte de confecção, transformada posteriormente em Cia. Brasileira de Moda).

Sendo a Juozas e a Del Rio pertencentes à mesma família (Pereira de Souza), hoje somente tem-se registro da Del Rio dirigida por Daniel Laureano Pereira de Souza, sediada em Maracanaú com 79 funcionários, confeccionando roupas íntimas. (Guia Industrial do Ceará, 2014). 
Das indústrias têxteis da década de 1970 que ainda se encontram ativas, temos a Unitêxtil, que entrou em concordata em 1990, fechando duas de suas unidades, a Santa Lúcia e a Santa Cecília, logo em seguida. "Naquela época, a unidade Santa Cecília, no bairro do Montese, em Fortaleza, também apresentava grande problema de custo-benefício. A empresa permaneceu apenas com uma unidade e demitiu 90\% dos funcionários”. (ARAGÃO, 2002, p. 108).

Constatamos que, na década de 1990, era crescente a migração de indústrias que vinham se instalar no Ceará. Como exemplo, temos a Lerma do Nordeste e a Haco Etiquetas que tem suas produções voltadas para fora do Estado. Somam-se a estas, as de maior porte que já existiam desde a década de 1970, como o Grupo Vicunha.

Ao contrário da gestão dos negócios pela hierarquia familiar outra característica do setor têxtil nos anos de 1990 é a "gestão científica", ou seja, uma gestão mais "profissional", no sentido de contratar executivos com experiência em gestão de empresas.

Ademais, enquanto o grande incentivador no alcance das metas e satisfação dos operários nos anos de 1980 eram os benefícios sociais, na década de 1990 a ênfase é nas políticas de gestão direcionadas ao alcance e participação nos resultados com desperdício zero e redução de acidentes de trabalho, com foco no treinamento contínuo.

A Vicunha, a Têxtil Bezerra de Meneses e a Santana Têxtil são alguns exemplos de indústrias que procuram acompanhar as novas exigências do mercado e que se deslocam na busca de se inserirem nas transformações globais, procurando não somente novos espaços para se alocar, como também passam por uma reestruturação produtiva com a consequente expansão para os espaços periféricos de Fortaleza e a implantação de fixos e fluxos (SANTOS, 1988) que acarretam novas formas tecnológicas, organizacionais e ocupacionais e maior mobilidade da força de trabalho, dada a fluidez dos sistemas de transportes e comunicações, o que interfere diretamente na estrutura socioespacial da RMF.

A política de atração de indústrias para municípios próximos à Capital ocasionou a consolidação nos anos de 1990 de outros eixos industriais, para além de Maracanaú e Maranguape, como nos municípios de Pacajus e Horizonte, notadamente ao longo da rodovia BR-116. A expansão industrial ocorre também no município de Eusébio, onde podemos encontrar hoje além da Haco, a Gurgel, Thunder, Adman, Cristal e Ramalho Têxtil. 
Depois deste resgate da indústria têxtil no Ceará até 2002, somos levados a questionar como sucede o desenvolvimento da indústria têxtil nesta década. Em Maracanaú, atualmente, temos as indústrias têxteis: Aleze, Delfa, Fiotex, Pemalex, Karsten, Tecelagem Alphatex, Têxtil União, Filati, Beatriz e Jangadeiro Têxtil, Cotefi Malhas.

Como consequência deste processo de expansão do capital industrial para além da capital, temos dentre as 337 indústrias ativas em Horizonte, as do ramo têxtil, como: Santana têxtil e Têxtil Andina. Em Pacajus, com um total de 312 indústrias ativas, também podemos encontrar indústrias do ramo têxtil (Vicunha) e de confecção (Arabril, Araujo e Brilhante/ Famel, Malwee).

Com a criação do Complexo Industrial e Portuário do Pecém (CIPP), em 2002, saiu fortalecido o eixo industrial Caucaia-São Gonçalo do Amarante, redefinindo-se o papel até então exercido por estes municípios na estrutura socioespacial metropolitana. Isto tem trazido inúmeras consequências para a dinâmica do mercado de trabalho metropolitano, a mobilidade da população e a demanda pelo solo urbano, com a expansão dos sistemas de objetos e ações, estreitando as relações destes municípios com a Capital.

Em Caucaia, que abrange também este complexo e é o segundo município do estado com maior quantitativo industrial,temos um total de 1.639 indústrias ativas onde podemos encontrar indústrias têxtil e de confecção, como: Fio Jeitoso, Ondas, Sitec Têxtil. Em Maranguape, há um total de 690 indústrias, sendo as indústrias têxteis e de confecção: Têxtil Itajaí do Nordeste, Hope do Nordeste, Micrel Benfio Têxtil, Banana Nanica Indústria de Confecções, Arte Modas, Rosa de Sarom. Aquiraz com a maior fonte de renda advinda do setor de serviços, notadamente ligado ao turismo, há também o investimento em indústrias, apresentando um quantitativo de 402 indústrias, dentre as quais, temos as do ramo têxtil e de confecção: Tramix, Marinho Têxtil, Visual Uniformes.

Cascavel, com um total de 268 indústrias ativas, conta com as seguintes indústrias têxteis e de confecção: Martêxtil, Herja, Bebevest. Em Pacatuba, que se beneficia da expansão das indústrias e dos conjuntos habitacionais concentrados inicialmente em Maracanaú, há um total de 368 indústrias ativas, dentre as quais, as têxteis e de confecção: Marisol, Diuncorpo Lingerie, Zanotti. Cabe destacar a representatividade da indústria Marisol (Santa Catarina, Rio Grande do Sul e Ceará-Pacatuba) neste município, pois emprega 1.575 pessoas somente nesta filial. 
Com a tendência de deslocamento regional das grandes empresas, estimuladas por incentivos fiscais e de infraestrutura fornecidos pelo Governo estadual, o Ceará vem aumentando sua relevância no cenário nacional, atraindo indústrias do setor têxtil e confeccionista. No entanto, como ressaltam Santos e Silveira (2001, p. 138) "algumas firmas nordestinas são apenas filiais de empresas sulistas do setor têxtil e de confecções". Além da Marisol, como exemplo, temos a Vicunha.

Todavia, o Ceará constitui o terceiro maior polo têxtil do País, com uma história de 132 anos, destacando-se em todo o processo de produção, desde o consumo do algodão até a produção do vestuário propriamente dito (Sebrae, 2014) ${ }^{1}$.

O atual estágio de desenvolvimento da indústria cearense resultou da descentralização da indústria nacional. Como, porém, o desenvolvimento do capitalismo é contraditório, temos a concentração da indústria têxtil em escala local, uma vez que no espaço cearense este crescimento fabril têxtil é significativo na RMF, notadamente na Capital,e, no Baixo Jaguaribe, em Jaguaruana, sendo 84 o número de indústrias têxteis neste município em 2012, apresentando um contínuo crescimento de estabelecimentos industriais têxteis, já que em 2002 era de 73 este quantitativo, conforme dados do IPECE.

A produção industrial têxtil ocorre de forma concentrada na RMF, já que em 2012 mais da metade das indústrias têxteis do Estado está na RMF, representando 63\% (399), enquanto em 2002 era de 44\% (190), ou seja, denota crescimento de indústrias têxteis na RMF perante o total do Estado, mesmo com a propaganda de interiorização industrial pelo Governo Estadual e a despeito da descentralização industrial do mundo.

Das indústrias têxteis que se destacam, há a Vicunha, a Têxtil Bezerra de Menezes e, em terceiro lugar, a Unitêxtil, que aumenta seu patrimônio, faturamento, vendas, mas permanece o mesmo quantitativo de empregados.

Ao contrário dos dados do IPECE (Instituto de Pesquisa e Estratégia Econômica do Ceará), que dividem o setor têxtil do de confecção, segundoo MTE/RAIS, os dados da indústria têxtil e confecção aparecem concatenados. Analisando os indicadores da RAIS no intervalo de 2002 a 2012, percebemos um crescimento contínuo de estabelecimentos industriais têxteis no Estado, senão vejamos a tabela seguinte. 
Tabela 1 - Estabelecimentos formais com vínculo empregatício na indústria têxtil, segundo os anos selecionados - Estado do Ceará

\begin{tabular}{|c|c|c|c|c|c|c|c|c|c|c|c|c|}
\hline Ano & 2002 & 2003 & 2004 & 2005 & 2006 & 2007 & 2008 & 2009 & 2010 & 2011 & 2012 & Total \\
\hline $\begin{array}{c}\text { Ind. } \\
\text { Têxtil }\end{array}$ & 2.095 & 2.216 & 2.274 & 2.390 & 2.502 & 2.738 & 2.984 & 3.125 & 3.385 & 3.557 & 3.612 & 30.878 \\
\hline
\end{tabular}

Fonte: MTE/RAIS.

O fato é que, respeitando suas respectivas metodologias, as duas fontes de dados estatísticos não divergem no essencial que constatamos em nosso estudo: enquanto em escala nacional, a concentração é na RMF no que concerne à RMF esta concentração se dá na Capital.

A representatividade da indústria têxtil se faz presente na economia cearense não somente pelo quantitativo de indústrias, produção, comercialização e empregos gerados, mas notadamente devidoas interações espaciais, como as vilas de operários e a ressignificação dos antigos espaços industriais têxteis,os sistemas técnicos necessários para a realização da produção e dos circuitos espaciais da produção etc.

Além das vilas industriais que ainda permanecem na configuração do espaço cearense, percebemos ainda a importância dos sistemas de objetos voltados à capacitação da mão de obra, uma vez que o treinamento dos trabalhadores é realizado pelo SENAI (Serviço Nacional de Aprendizagem Industrial), utilizando-se recursos do FAT (Fundo de Amparo ao Trabalhador).

Além do SENAI, há no Estado uma série de sistemas de objetos voltados à qualificação da mão de obra industrial e estudos voltados ao setor industrial: SESI (Serviço Social da Indústria), Instituto Euvaldo Lodi, Instituto de Desenvolvimento Industrial do Ceará, Centro de Treinamento Técnico do Ceará, sem falar que o Ceará tem o maior programa de ensino profissionalizante do Brasil, não esquecendo também a importância dos IFCEs (Instituto Federal de Educação, Ciência e Tecnologia do Ceará).

Espaços outrora ocupados por trabalhadores e por indústrias têxteis e que, acompanhando as transformações na cidade ao longo do tempo, hoje servem a novos usos. Por exemplo a antiga indústria Progresso, no centro da cidade, que passou a ser usada para o comércio de confecção. A antiga Fabrica de Redes São José, na avenida Filomeno Gomes, nas proximidades da Escola de Aprendizes de Marinheiros e da Igreja Nossa Senhora dos Navegantes onde está sendo construído o shopping Boulevard Jacarecanga, inserido no projeto de shoppings nos bairros da cidade de 
Fortaleza-CE. Em frente ao espaço antes ocupado pela Finobrasa (atual Vicunha em Pacajus e Maracanaú), na Av. Humberto Monte, esquina com Sargento Hermínio, no bairro Presidente Kennedy, está sendo construído o Shopping Rio Mar Norte. Ademais, espaços de antigas indústrias servem atualmente para outros fins, como as instalações da antiga Vilejack Jeans, moradia irregular para pessoas menos favorecidas economicamente que através da autoconstrução passam a viver nestes antigos espaços.

A saída de muitas indústrias deixou grandes vazios urbanos territoriais, dentre os quais, o da antiga Oficina do Urubu, da extinta Rede de Viação Cearense (RVC). Nos espaços que passaram a configurar vazios urbanos, com a desativação ou relocalização industrial, fruto da atual política industrial do Estado do Ceará, a Política de Desenvolvimento Produtivo (PDP For), em 2009, definiu inúmeros lotes como ZEIS3. Nesses vazios deixados por antigas indústrias, estão sendo implantados pela prefeitura conjuntos habitacionais para realocar famílias situadas em áreas de risco ou com infraestrutura de moradia muito precária que foram removidas com o Projeto Vila do Mar (Muniz, 2014).

Ações da prefeitura como esta interferem na dinâmica urbana da cidade, aproveitando os instrumentos previstos no Plano Diretor. Sem esquecer, também a importância destas ações para fazer frente à crescente ação dos setores imobiliários que têm disputado com o poder público os vazios urbanos. Isto ocorre diante da oportunidade de investimento em empreendimentos residenciais e comerciais de médio e até alto padrão, com a presença local de equipamentos e serviços essenciais como, escolas, postos de saúde, bancos, shoppings, comércio e da excelente localização da Av. Francisco Sá na malha urbana da cidade, com tráfego de transportes que dão acesso a vários locais da cidade de Fortaleza e Região Metropolitana.

Ocorre a requalificação de bairros e são reassentadas famílias em antigos espaços industriais. Com a saída ou falência de inúmeras indústrias e a crescente especulação imobiliária, são construídos condomínios residenciais e conjuntos habitacionais populares, onde se alocam as famílias de baixa renda. É assim que antigos espaços industriais, hoje, passam a ser espaços de especulação imobiliária para ocupação residencial, de comércio ou serviços.

Com a descentralização industrial da zona oeste de Fortaleza observamos, em pesquisa realizada por Muniz (2002) uma reconfiguração espacial, uma nova função exercida por este espaço que deixa de ser 
predominantemente de sustentação e valorização industrial ao mesmo tempo em que se transforma em espaço residencial, de comércio e serviços. Observamos ainda na zona oeste o crescimento de subcentros comerciais, visando distribuir uma gama de produtos para um crescente mercado consumidor, constituído predominantemente por assalariados.

\section{Considerações Finais}

Diante dos principais tipos de indústrias têxteis presentes no espaço cearense percebemos, dentre outras coisas, como se dá o crescente investimento no capital industrial, nos levando a afirmar que as indústrias se diferenciam tanto no ramo em que atuam, quanto no porte, existindo tanto pequenas como médias e grandes indústrias, como também na origem do capital investido, não dependendo mais somente de investimentos locais. Por outro lado, a existência do capital externo não é garantia de sua permanência e é questionável a qualidade dos empregos gerados e o escoamento dos lucros, levando a necessidade de desenvolvimento de estudos quanto a atual política industrial de isenção e concessão de uma série de benefícios para alocar o capital nacional ou internacional.

Foi possível perceber a dinâmica da indústria têxtil no espaço cearense ao longo do tempo e constatar que as interações da produção têxtil vão além do aspecto econômico e social, evidenciando-se as transformações notadamente no espaço urbano, dentre outras coisas com os novos espaços da produção industrial e as novas funções de antigos espaços industriais.

Desta forma, vislumbrou-se a necessidade de entender o presente como um processo, numa análise, mesmo que sucinta da produção industrial têxtil, mas que integrasse o processo social, forma e função espacial, levando em conta o contexto maior para os padrões de cada época, ou seja, as transformações socioespaciais e as temporalidades.

A indústria têxtil, além de ter ligação com o espaço, história de ocupação cearense, vinculado assim, à economia estadual, causou ao longo do tempo transformações socioespaciais notáveis, não só nas cidades de origem como também onde permanece e onde mantém relações comerciais por meio do espaço da circulação de seu produto final e compra de matérias-primas.

A indústria têxtil cearense tem sua produção bastante heterogênea, no que diz respeito às diversas possibilidades de utilização e combinação 
de matérias-primas utilizadas, ao que se adicionam as intensidades variáveis de utilização de capital e mão de obra em cada etapa da produção, aos diferentes padrões de concorrência e estratégias empresariais, além de uma gama bastante ampla de opções quanto a escala de produção, tecnologia utilizada e as formas de organização produtiva.

Estas opções variam de acordo com a especificação pretendida do produto final (aparência, textura, padronagem, flexibilidade etc.) e com o mercado que se quer atingir (de uso doméstico ou industrial, de produtos de moda ou padronizados, para faixas de renda elevada ou baixa etc). Tal diversidade só vem revelar a pertinência deste estudo na busca de compreender as especificidades no tempo e espaço da produção industrial têxtil.

Mesmo saindo da era do capital industrial e diante da crescente valorização do capital na esfera financeira, a autonomia do setor financeiro é relativa, em decorrência das inter-relações do capital financeiro na esfera produtiva. Ademais, a indústria têxtil continua ocupando espaço de singular importância no espaço cearense, impulsionando os demais setores produtivos.

\section{Notas}

1 Disponível em: <http://www.sebrae2014.com.br/sebrae/sebrae\%202014/ boletins/fortaleza_boletim_2014_julho.pdf.>.

\section{Referências}

AMARAL FILHO, J. do. Ajustes estruturais, novas formas de intervenção pública e novo regime de crescimento econômico no Ceará. In: GONÇALVES, M. F.; BRANDÃO, C. A.; GALVÃO, A. C. F. (Org.). Regiões e cidades, cidades nas regiões: o desafio urbano-regional. São Paulo: UNESP: ANPUR, 2003. $\overline{\text { INESP }}, 2000$.

. (Org.). Federalismo fiscal e transformações recentes no Ceará. Fortaleza:

AMORA, Z. B. Indústria e espaço no Ceará. In: SILVA, J. B. da; CAVALCANTE, T. C.; DANTAS, E. W. C. (Org.). Ceará: um novo olhar geográfico. Fortaleza: Edições Demócrito Rocha, 2005.

ANDRADE, M. J. F. de S. Onde moram os operários: vilas operárias em Fortaleza 1920-1945. 309 f. Dissertação (Mestrado em Arquitetura e Urbanismo) Universidade Federal da Bahia, Salvador, 1990. 
ANUÁRIO DE FORTALEZA. Conhecendo Fortaleza. 2012-2013. Disponível em: <http://www.anuariodefortaleza.com.br/>. Acesso em: 30 out. 2015.

ARAGÃO, E. F. (Coord.). O fiar e o tecer: 120 anos da indústria têxtil no Ceará. Fortaleza: SINDITÊXTIL / FIEC, 2002.

. A trajetória da indústria têxtil no Ceará: o setor de fiação e tecelagem 1880-1950; Projeto História do Ceará: política, indústria e trabalho. Fortaleza: Edições Universidade Federal do Ceará Stylus Comunicações, 1989.

BRASIL. Ministério do trabalho e emprego. Dados estatísticos de Relação Anual de Informações Sociais (RAIS). Disponível em <http://portal.mte.gov.br/rais/>. Acesso em: 14 jun. 2016.

BRASIL. Ministério do desenvolvimento, indústria e comércio. Brasil Maior. Inovar para competir. Competir para Crescer. 2014. Disponível em <http:// www.brasilmaior.mdic.gov.br/wp-content/uploads/cartilha_brasilmaior.pdf $>$. Acesso em: 14 jun. 2016.

FIEC. Federação das indústrias do Estado do Ceará. Guia Industrial do Ceará. Disponível em: <http://www2.sfiec.org.br/portalv3/sites/guia2014/?st=acessorestrito-consulta $>$. Acesso em: 30 out 2016.

GIRÃO, R. História econômica do Ceará. 2. ed. Fortaleza: UFC - Casa de José de Alencar/Programa Editorial, 2000. 470 p.

INSTITUTO DE PESQUISA E ESTRATÉGIA ECONÔMICA DO CEARÁ. Perfil setorial - Vestuário 2013. Fortaleza, 2013. Disponível em: < http:www.ipece. ce.gov.br>. Acesso em: 1 ago. 2016.

LIMA, L. C. Produção do Espaço, Sistemas Técnicos e Divisão Territorial do Trabalho. Scripta Nova. Revista Electrónica de Geografía y Ciencias Sociales. Universidad de Barcelona, v. VI, n. 119 (63), 1 ago. 2002. Disponível em: < www. ub.es/geocrit>. Acesso em: 14 jun. 2016.

MUNIZ, A. M. V. A dinâmica da indústria têxtil no espaço metropolitano de Fortaleza. Tese (Doutorado em Geografia) - Programa de Pós-Graduação em Geografia da Universidade Federal do Ceará, UFC, Fortaleza, 2014.

. As transformações do espaço urbano na zona da Francisco Sá. II Encontro de Pós-Graduação e Pesquisa da Unifor, Fortaleza-Ce, abril de 2002, p. 131, impresso.

. Aspectos infra-estruturais de Horizonte frente à reorganização espacial. In: Anais da IV Semana Universitária da UECE, Fortaleza, 1999.

. Produção do Espaço Metropolitano de Fortaleza e a Dinâmica Industrial. Revista Mercator, Fortaleza, v. 14, n. 3, p. 61-74, set./dez. 2015.

NOBRE, G. O processo histórico de industrialização do Ceará. 2. ed. Fortaleza: FIEC, 2001.

OLIVEIRA, F. de. Elegia para uma re(li)gião: SUDENE, Nordeste, planejamento e conflito de classe. 2. ed. Rio de Janeiro: Paz e Terra, 1977.

SANTOS, M. Pensando o espaço do homem. São Paulo: Hucitec, 1980. . Metamorfose do espaço habitado. São Paulo: Hucitec, 1988. 
. A natureza do espaço: técnica e tempo. Razão e emoção. 4. ed. São Paulo: $\overline{\text { Hucitec, }}_{2008 .}$

SEBRAE. SERVIÇO BRASILEIRO DE APOIO ÀS MICRO E PEQUENAS EMPRESAS. Disponível em: <www.sebrae.com.br>. Acesso em: 1 ago. 2016.

SILVA, J. B. da. A Região Metropolitana de Fortaleza. In: CAVALCANTE, T. C.; DANTAS, E.; SILVA, J. B. da. (Org.). Ceará: um novo olhar geográfico. Fortaleza: Edições Demócrito Rocha, 2005.

. Conhecendo Fortaleza: o sistema de transporte urbano e a garantia do ir e vir na cidade. In: ANUÁRIO DE FORTALEZA 2012-2013. Fortaleza: Edições Demócrito Rocha, 2012.

A cidade contemporânea no Ceará. In: SOUZA, S. de (Org.). Uma nova história do Ceará. Fortaleza: Edições Demócrito Rocha, 2002.

. O algodão no processo de organização do espaço. In: SOUSA, S. (Org.). História do Ceará. Fortaleza: UFC/Fundação Demócrito Rocha, 1994.

SOUSA, E. Álbum do Jaguaribe. Belém: Gráfica Amazônia, 1922.

STEIN, S. Origens e Evolução da Indústria Têxtil no Brasil - 1850/1950. Rio de Janeiro: Campus. 1979. Original: Stein, Stanley - The Brazilian Cotton Manufacture - Textile Enterprise in an Underdeveloped area: 1850-1950, Cambridge, Massachusetts, 1957, Harvard Press.

TAKEYA, D. Europa, França e Ceará: as origens do capital estrangeiro no Brasil. Natal: UFRN, 1995.

Alexsandra Maria Vieira Muniz - É bacharel e licenciada em Geografia pela Universidade Estadual do Ceará. Possui Mestrado em Geografia pela mesma Universidade e Doutorado em Geografia pela Universidade Federal do Ceará. Atualmente é pesquisadora do Laboratório de Estudos Urbanos e Regionais (LAPUR) e do Observatório das Metrópoles. 